\title{
Evaluation of structural isotropy of Cr-V ledeburitic steel made by powder metallurgy of rapidly solidified particles
}

\author{
M. Nemec ${ }^{1 *}$, P. Jurči ${ }^{2}$, P. Kosnáčová ${ }^{1}$, M. Kučerová ${ }^{3}$ \\ ${ }^{1}$ Slovak University of Technology in Bratislava, Faculty of Materials Science and Technology in Trnava, \\ Institute of Safety, Environment and Quality, Botanická 49, 91724 Trnava, Slovak Republic \\ ${ }^{2}$ Slovak University of Technology in Bratislava, Faculty of Materials Science and Technology in Trnava, \\ Institute of Materials Science, Bottova 25, 91724 Trnava, Slovak Republic \\ ${ }^{3}$ Slovak University of Technology in Bratislava, Faculty of Materials Science and Technology in Trnava, \\ Institute of Industrial Engineering and Management, Paulínska 16, 91724 Trnava, Slovak Republic
}

Received 16 June 2015, received in revised form 7 February 2016, accepted 20 July 2016

\begin{abstract}
A microstructure with a particular focus on carbides amount in PM ledeburitic cold work tool steel VANADIS 6 was analysed in three independent directions using the linear quantitative method, in order to determine the anisotropy of the material. The obtained quantitative results were analysed by statistical methods. To obtain sufficiently large statistical files, twenty-five micrographs were acquired from each direction, using the scanning electron microscopy working in both the secondary electron detection mode and the backscattered electrons detection regime. The obtained results infer that there is no significant difference between the quantities of carbides in three independent directions. In other words, the material is isotropic with a probability of $95 \%$, hence, the initial orientation of semi-product can be disregarded in sampling. A significant difference in measured amounts of carbides was established between two detection regimes used for the quantification. Thereby it was confirmed that the backscattered electrons detection regime has lower resolution limit than the mode of detection of secondary electrons.
\end{abstract}

Key words: isotropy of material, statistical hypothesis testing, scanning electron microscopy

\section{Introduction}

Chromium and chromium-vanadium ledeburitic steels have been introduced into an industry during the World War I. They have early gained a great interest in cold work tooling, due to their high hardness, high compressive strength, and good or excellent wear performance. These properties are generally achieved through proper heat treatment, which results in the microstructure consisting of tempered martensite, carbide precipitates and undissolved eutectic and a certain amount of secondary carbides.

In classical manufacturing line, these materials are produced by slow solidification of the melt in ingots having hundreds of kilograms. At these circumstances, high carbon content together with high level of alloying leads to the formation of coarse carbides and net- works, which makes it impossible to use these materials in as-cast condition due to low toughness and ductility. The size of individual carbide particles as well as the thickness of eutectic networks (austenite + carbides) increase with the decreasing cooling rate during solidification, as quantified recently by Pirtovšek et al. [1] and Kheirandish et al. [2] for the AISI D2 and AISI D3 steel, respectively. To improve the mechanical properties, the materials are hot worked. This procedure leads to fragmentation of carbide networks, however, resulting carbide particles are distributed parallel to the working direction in bands and agglomerates whereas the dimensions of the agglomerates depend on the quantitative characteristics of the initial as-cast microstructure of the steel [1]. In addition, spheroidization of the carbides and their coagulation and growth are occurring as a result of the

\footnotetext{
*Corresponding author: tel.: +421 902535 863; e-mail address: nemec1988@gmail.com
} 
effort of the material to minimize the surface energy of the particles $[3,4]$. Therefore, wrought microstructure of $\mathrm{Cr}$ - and $\mathrm{Cr}-\mathrm{V}$-ledeburitic steels is classified as anisotropic from the point of view of mechanical properties since they are different in a longitudinal and transverse direction to the previous hot working [58]. Moreover, the carbide banding is responsible for non-uniform distortion in heat treatment [9].

Several methods have been established to make a refinement of the microstructure of $\mathrm{Cr}$ - and $\mathrm{Cr}-\mathrm{V}$ ledeburitic tool steels. Most part of them is related to increasing the cooling rate during solidification and thereby reducing the segregations [10-15]. The first method enabling considerable reduction of segregation and production of materials with excellent microstructure and mechanical properties is the powder metallurgy (PM) of rapidly solidified particles [10, 11, 14]. The method combines the gas spraying of the melt into small droplets and the consolidation of small powder particles into the compact material using the hot isostatic pressing. However, particular processes in powder metallurgy like electro-slag remelting or vacuum arc remelting of the alloy prior to the gas spraying, the gas spraying itself, and the hot isostatic pressing increase the final material cost significantly. The second important production method resulting in microstructural refinement of high alloyed steels is the spray forming. The spray forming is a less expensive alternative production method to the PM of rapidly solidified particles because the material is manufactured in a single process $[5,15]$. Unfortunately, the solidification conditions in spray forming do not enable to achieve as high cooling rate as in the PM. Hence, the resulting microstructure is coarser than what is achieved by PM.

Generally, it is believed that the microstructure of PM made ledeburitic steels is not only free of macrosegregations, but it is also free of carbide banding typical for wrought materials. However, PM ledeburitic steels are subjected to hot working, also, after consolidation, in order to make the semi-finished products (bars, sheets, rods, etc.) that are then delivered to the end-users of the materials. Due to this fact, one can expect that some anisotropy can occur in PM materials, also. The present paper is focused to statistical assessment of structural anisotropy in PM ledeburitic steel Vanadis 6 , manufactured by Uddeholm AB, Sweden [16]. This research was designed as a part of the scientific project, and it was aimed to the investigation whether the microstructure of as-delivered steel can be disregarded when sampling or not.

\section{Experimental}

A commercially available PM Cr-V cold work tool steel Vanadis $6(2.1 \% \mathrm{C}, 7 \% \mathrm{Cr}, 6 \% \mathrm{~V}$, Fe bal. $)$ was

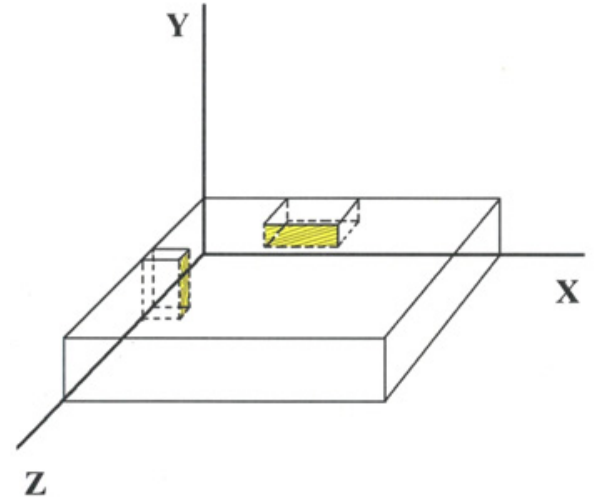

Fig. 1. Sampling from the delivered semi-product.

used for the experimental purposes. Specimens for the quantitative investigations were cut off from the asreceived thick sheet (thickness of $16 \mathrm{~mm}$ ) in two perpendicular and independent directions, Fig. 1. These specimens were prepared by standard metallographic preparation line and finally polished with $1 \mu \mathrm{m}$ diamond slurry. A standard etching using a Villela-Bain reagent was used before the microstructural observations or, the samples with no etched surface were used for the SEM in selected cases.

Microstructural examinations were completed using the light microscope Neophot 32 and the scanning electron microscope. For the scanning electron microscopy (SEM), a JEOL JSM 7600F apparatus, equipped with an EDS-detector Oxford Instruments, was used. The microstructure was recorded in both the secondary electron (SE) detection regime and the backscattered electron (BE) detection regime. For each independent direction and detection regime, twenty-five micrographs (the one representative sample) were recorded.

The carbide orientation was quantitatively analysed in three independent directions denoted as $X$, $Y$ and $Z$. Each recorded microstructure of specimen was evaluated by using linear quantitative analysis. In Fig. 2 it is shown an example how the microstructure was evaluated in the backscattered electron detection regime. Ten parallel lines were placed through the micrograph, and the linear fractions of both the $\mathrm{M}_{7} \mathrm{C}_{3}$ - and MC-carbides were measured by the schedule described below. At this place, it should be noted that the two types of carbides differ one of the second in the BE yield, which makes it possible to differ them conclusively. Dark particles represent the MC-carbides since they contain a higher amount of lower atomic carbon and vanadium while light particles are the $\mathrm{M}_{7} \mathrm{C}_{3}$-carbides containing a higher portion of chromium and iron, respectively.

Each parallel line intersects the carbides and produces abscissas as a result of such interaction, Fig. 2. 


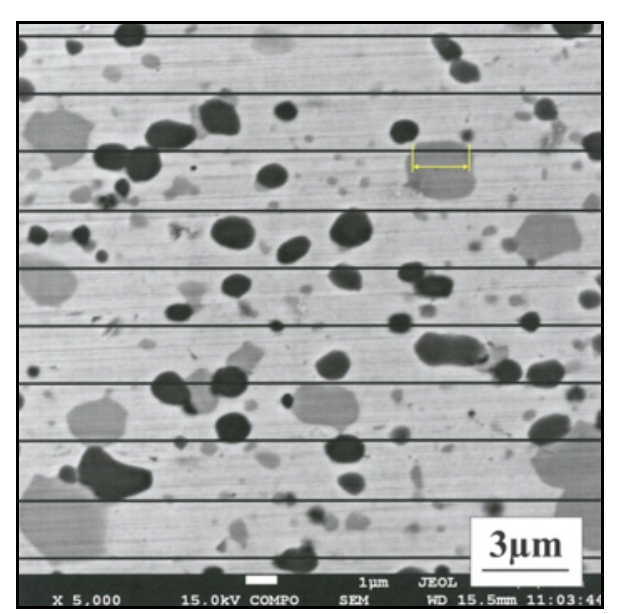

Fig. 2. An example of the application of linear quantitative analysis of carbide orientation in the $X$ direction, backscattered electrons regime.

The sum of abscissas, separately for the $\mathrm{M}_{7} \mathrm{C}_{3}$ - and for the MC-carbides was calculated in each parallel line. For a linear fraction of given carbide phase, the total length of the line was divided by the sum of abscissas established for given phase. The linear fractions for the $\mathrm{M}_{7} \mathrm{C}_{3}$ - and $\mathrm{MC}$-carbides were calculated for each parallel line on the micrograph. Afterwards, the mean value of linear fractions was calculated as an average of linear fractions established for each of ten parallel lines on the micrographs. To obtain statistical data files, twenty-five micrographs were taken into the consideration for each independent direction recorded in the regime of detection of backscattered electrons and the same number of micrographs recorded by the detection of secondary electrons.

In the secondary electron detection regime, the same method was applied to the investigations. The following remark should be made in this respect: There is no difference between $\mathrm{M}_{7} \mathrm{C}_{3}$ carbide and the MC-phase in the secondary electron yield. Hence, EDS maps of chromium and vanadium were used to assist for the section of the phases, Fig. 3.

The obtained results from quantitative analysis were statistically evaluated and analysed, since, as well known, quantitative microstructural analysis requires the use of statistical methods since the results represent statistical data files, which clearly manifest statistical properties. The method used for the statistical analysis was the statistical testing of signification or, in other words, statistical hypothesis testing. The method is based on the assumption that the representative sample (the result of the determination of linear fraction), which is obtained by random sampling, represents the properties of the whole data file.

The statistical testing can be denoted as a rule for summarizing any data file generated by the mechanism. The null hypothesis is confirmed or rejected

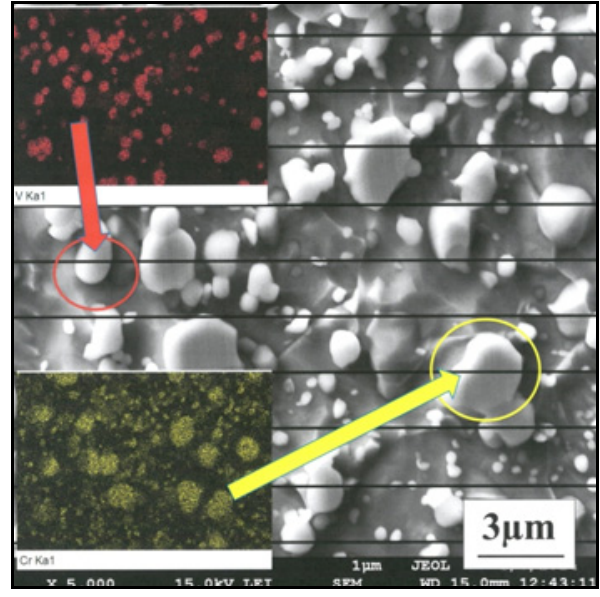

Fig. 3. An example of the application of linear quantitative analysis of carbide orientation in the $X$ direction, secondary electrons regime.

by the statistical test. If the tested data is consistent with the hypothesis, then we shall conclude that the hypothesis is true. If the data is inconsistent with the hypothesis, we conclude that the hypothesis is false. The null hypothesis might be that the true effects of the conditions are all equal to zero. The null hypothesis gives a more specialized and more tentative assumption that is to be tested within the statistical test $[17,18]$.

The statistical hypothesis test is based on an analysis interference of statistical characters like probability distribution or random variable. The hypothesis is a statement about the parameters of one or more probability distributions [18]. For the current statistical analysis, a 2-sample test for analysis of signification between two data files was used. The statistical properties, namely mean values and standard deviations of the data files obtained by the linear analysis, were used for the 2-sample tests.

Two case analyses were carried out. The first one pertained the possible structural anisotropy of investigated tool steel and, in order to make the statistical assessment, the 2-sample test was used to determine the differences in linear carbide amounts between the direction $X$ and $Y, Y$ and $Z$ and $X$ and $Z$, respectively. The second case pertained to the possible differences in linear carbide amount determined via the secondary electron detection regime, and that obtained via the backscattered electron detection regime.

The threshold value, so-called "alpha value", which presents the I. error type (error of the rejecting the null hypothesis when it is true) was chosen to $5 \%$ (standard value). In other words, the I. error type is called as the level of significance [18].

The overall null hypotheses, $\mathrm{H}_{0}$, were expressed as follows:

$-\mathrm{H}_{0}$ for the statistical testing of material isotropy: 


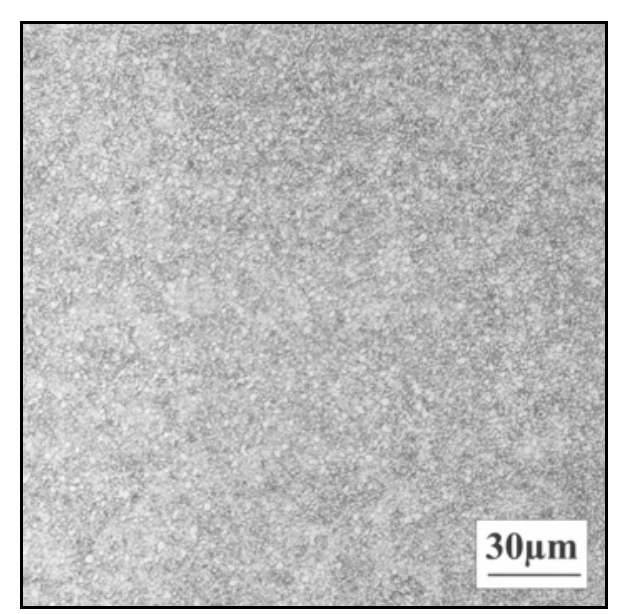

Fig. 4. Light micrograph showing the microstructure of as-received steel.

"The linear fractions of carbides are significantly different depending on the direction of examination whereas the detection regime was kept the same."

$-\mathrm{H}_{0}$ for the statistical testing of deviation between two electron detection regimes:

"The linear fractions of carbides are significantly different depending on the used detection regime in the same direction."

\section{Results and their discussion}

\subsection{Description of the microstructure of the analysed material}

Light micrograph, Fig. 4, shows the as-annealed microstructure of the Vanadis 6 steel. The material consists of the matrix and fine, uniformly distributed carbides. No carbide banding or clusters are visible on the micrograph at low magnification. It should be noted here that the use of the light microscope is not appropriate for the assessment of details in the microstructure, due to its low-resolution limit. Therefore, all the quantitative investigations were then carried out using the scanning electron microscope.

Detail SEM micrograph, Fig. 5a and corresponding EDS-maps of vanadium (Fig. 5b) and chromium (Fig. 5c) show that the carbides are different in terms of their nature and, as reported elsewhere [19, 20], in terms of their origin also. According to these results, the carbides can be differed as:

(i) Eutectic particles (ECs) that are of the nature of vanadium-rich MC-phase.

(ii) Secondary particles (SCs), formed mainly by the $\mathrm{M}_{7} \mathrm{C}_{3}$ phase, which is rich in chromium and iron.

(iii) Eutectoid formations, designed as spheroidized pearlite (SP). These particles are also based on the $\mathrm{M}_{7} \mathrm{C}_{3}$-carbide.
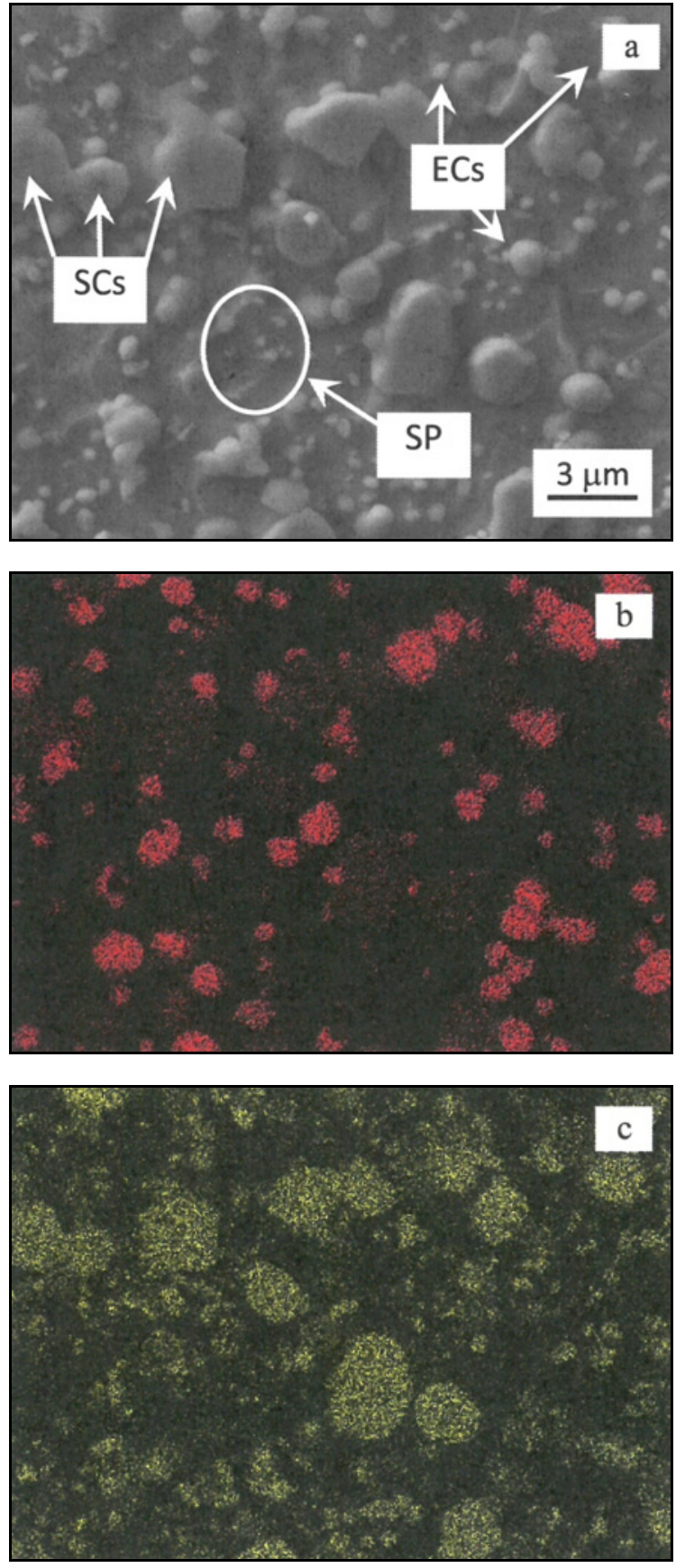

Fig. 5. SEM micrograph (SE detection regime) (a) and corresponding EDS maps of vanadium (b) and chromium (c) showing as-received microstructure of Vanadis 6 steel.

SEM micrograph obtained by the detection of backscattered electrons, Fig. 6, enables to make a clear distinction between the $\mathrm{M}_{7} \mathrm{C}_{3}$-carbides and $\mathrm{MC}$ -carbides, owing to different $\mathrm{BE}$ yield. The first ones appear grey due to a higher amount of higher atomic chromium and iron while the MC appear almost black since they contain lower atomic vanadium in the amount of more than $50 \mathrm{wt} . \%$. Unfortunately, the resolution limit of the detection of backscattered elec- 


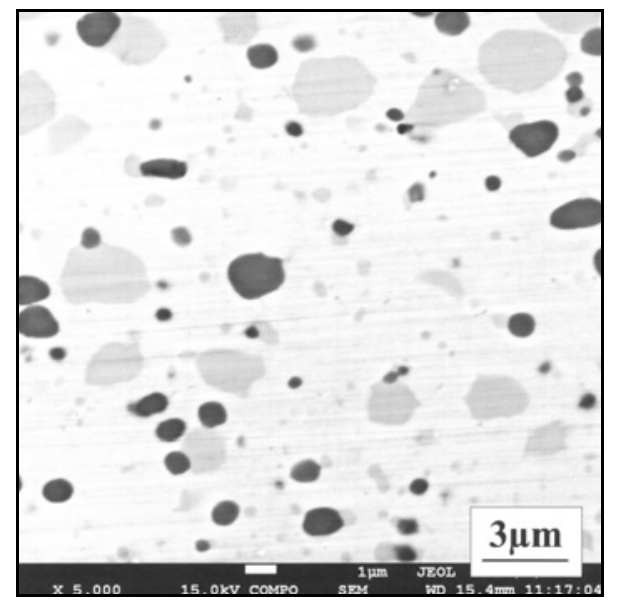

Fig. 6. SEM micrograph (BE detection regime) showing as-received microstructure of Vanadis 6 steel.

trons is lower than what can be achieved by the detection of secondary electrons. Hence, there is a risk to miss some carbide particles when making a quantitative analysis. Thus, the micrographs made in this regime have been used for the verification of obtained results only.

The following remark should be made here: During the hot forming, the eutectoid and a certain amount of secondary carbides are dissolved in the austenite while other parts of secondary carbides and eutectic carbides remain unaffected by the thermal treatment. Therefore, only eutectic carbides and secondary carbides were taken into consideration in the quantitative analysis and it was believed that the eutectoid particles could have been disregarded because they appear in the microstructure as a result of slow cooling from the temperature of hot working.

\subsection{Statistical testing of material isotropy in the backscattered electron (BE) detection regime}

The results from quantitative linear analyses for each independent direction (Fig. 1) were analysed by using the Minitab statistical software. The null hypotheses for statistical testing of isotropy in the backscattered electrons detection regime were expressed as follows:

- The mean value of the measured linear fractions of the $\mathrm{M}_{7} \mathrm{C}_{3}$-carbides and that of the $\mathrm{MC}$-carbides in the $X$ direction are significantly different from the mean value of the measured linear fractions of the $\mathrm{M}_{7} \mathrm{C}_{3^{-}}$(or MC-carbides) in the $Y$ direction.

- The mean value of the measured linear fractions of the $\mathrm{M}_{7} \mathrm{C}_{3}$-carbides and that of the MC-carbides in the $Y$ direction are significantly different from the mean value of the measured linear fractions of the $\mathrm{M}_{7} \mathrm{C}_{3^{-}}$(or MC-carbides) in the $Z$ direction.

- The mean value of the measured linear fractions of the $\mathrm{M}_{7} \mathrm{C}_{3}$-carbides and that of the $\mathrm{MC}$-carbides in the $X$ direction are significantly different from the mean value of the measured linear fractions of the $\mathrm{M}_{7} \mathrm{C}_{3^{-}}$(or MC-carbides) in the $Z$ direction.

An example of a diagnostic report from software Minitab with basic statistical characteristics is in Fig. 7. The diagnostic report describes the data files obtained by the analysis of $\mathrm{M}_{7} \mathrm{C}_{3}$-carbides in $\mathrm{BE}$ detection regime, for the $Y$ and $Z$ independent directions. The chart on the left side of the report denotes the linear fractions in the direction $Y$, and that on the right side illustrates the linear fractions in the direction $Z$. The green line in the chart represents the mean value of measured linear fraction of $\mathrm{M}_{7} \mathrm{C}_{3}$-carbides in directions $Y$ and $Z$, respectively. The $x$-axis of the chart is the number of sample or the sample size while the $y$-axis denotes the obtained linear fractions of the carbides for randomly acquired micrographs. These clear illustrations of mean and variability indicate independent differences between tested directions.

Figure 8 shows the summary report from Minitab software for the mean value of the measured linear fractions of the $\mathrm{M}_{7} \mathrm{C}_{3}$ carbides in $Y$ vs. $Z$ independent directions, respectively, for the micrographs acquired in the BE detection regime. This summary report declares the exact results of statistical testing

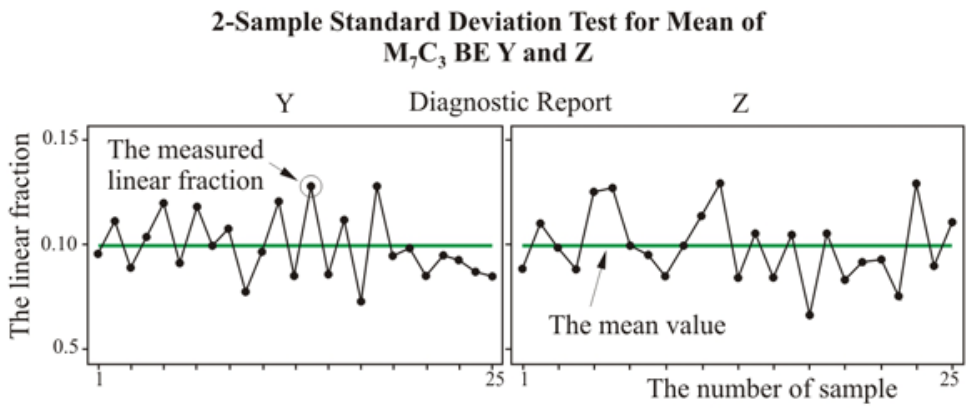

Fig. 7. Diagnostic report from Minitab for the mean value of the measured linear fractions of the $\mathrm{M}_{7} \mathrm{C}_{3}$-carbides in $Y$ vs. $Z$ independent directions in BE detection regime. 


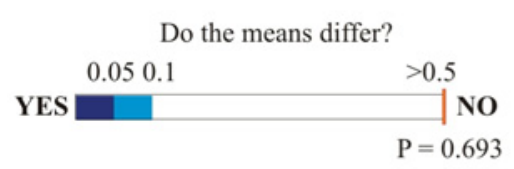

The standard deviation of $\mathrm{Y}$ is not significantly different from $\mathrm{Z} \Rightarrow$ $\mathrm{p}<0.5$

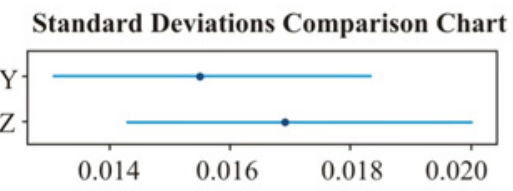

Distribution of Data

Compare the spread of the samples

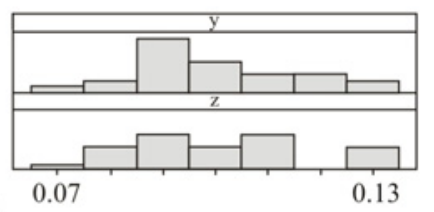

(b)

\begin{tabular}{lcc} 
Statistics & $\mathbf{B E ~} \mathbf{M}_{7} \mathbf{C}_{3} \mathbf{Y}$ & $\mathbf{S E ~} \mathbf{M}_{7} \mathbf{C}_{3} \mathbf{Z}$ \\
\hline Sample size & 25 & 25 \\
Mean & 0.099493 & 0.100070 \\
Standard deviation & 0.015491 & 0.016901 \\
$\quad 95 \% \mathrm{Cl}$ & $0.0124 ; 0.0209$ & $0.0134 ; 0.0232$
\end{tabular}

Fig. 8. Summary report from Minitab for the mean value of the measured linear fractions of the $\mathrm{M}_{7} \mathrm{C}_{3}$-carbides in $Y$ vs. $Z$ independent directions in BE detection regime: (a) graphs, (b) statistics.

Ta b le 1. Summarizing table of results obtained in the BE detection regime

\begin{tabular}{|c|c|c|c|c|c|c|c|c|c|c|c|}
\hline \multicolumn{12}{|c|}{$\mathrm{BE}$} \\
\hline \multicolumn{6}{|c|}{$\mathrm{M}_{7} \mathrm{C}_{3}$} & \multicolumn{6}{|c|}{$\mathrm{MC}$} \\
\hline & $X$ & & $Y$ & & $Z$ & & $X$ & & $Y$ & & $Z$ \\
\hline$X$ & - & No & $P=0.443$ & No & $P=0.647$ & $X$ & - & No & $P=0.179$ & No & $P=0.230$ \\
\hline$Y$ & - & & - & No & $P=0.693$ & $Y$ & - & & - & No & $P=0.900$ \\
\hline$Z$ & - & & - & & - & $Z$ & - & & - & & - \\
\hline
\end{tabular}

of material isotropy. As shown here, the $p$-value was determined by 0.05 . The calculated $P$ testing character was 0.693 , i.e. it was higher than the chosen $p$-value. Therefore, the null hypothesis was rejected. In other words, the mean values of linear fractions of $\mathrm{M}_{7} \mathrm{C}_{3}$-carbides in the $Y$-direction and those in the $Z$-direction are not significantly different. The data representing the standard deviations, right part of Fig. 8, assist in making a more clear comparison between the files obtained by statistical analysis of linear fractions of $\mathrm{M}_{7} \mathrm{C}_{3}$-carbides in the $Y$ and $Z$ independent directions. As shown in the histograms here, the distribution of the data in the $Y$ direction is close to the distribution of the data in the $Z$ direction. One can thus claim that the standard deviations comparison chart, the histograms and also the statistics of the mean values and the standard de- viation show that the linear fractions of the $\mathrm{M}_{7} \mathrm{C}_{3}$ -carbide measured in the $Y$-direction do not differ significantly from those obtained in the $Y$-direction.

The statistical testing of the material isotropy consisted of six tests because the material contained two types of carbides phases, which were measured in three independent directions. Summary of the obtained results is shown in Table 1. Here, "No" denotes no significant difference between linear fractions of carbides obtained in tested directions and "Yes" represents the case when the difference in linear fractions is statistically significant. As is clearly evident, the $P$ testing characters are higher than the pre-determined $p$-value (0.05), which means that the null hypothesis was rejected for all the cases of testing. In other words, one can conclude that the linear fractions of both types of carbide phases are directionally independent, which 


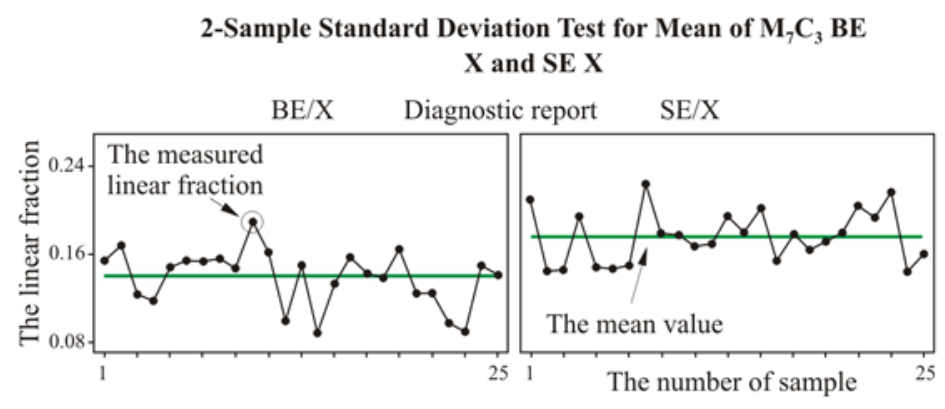

Fig. 9. Diagnostic report from Minitab for the mean value of the measured linear fractions of the $\mathrm{M}_{7} \mathrm{C}_{3}$-carbides in $X$ directions in BE vs. SE detection regime.

assists to make a decision that the ledeburitic tool steel Vanadis 6 is isotropic.

\subsection{Statistical testing of the deviation between two electron detection regimes}

The second part of the experiment was focused on the investigation whether the results obtained by the recording of microstructures in the SE detection mode differed significantly from those obtained by recording the microstructure in the $\mathrm{BE}$ detection regime. The null hypotheses for statistical testing of deviation between two electron detection regimes were expressed as follows:

- The mean value of the linear fractions of the $\mathrm{M}_{7} \mathrm{C}_{3}$-carbides and that of the MC-carbides in the $X$ direction in $\mathrm{BE}$ detection regime are significantly different from the mean value of the linear fractions of the $\mathrm{M}_{7} \mathrm{C}_{3}$ - (or MC-) carbides in the $X$ direction in $\mathrm{SE}$ detection regime.

- The mean value of the linear fractions of the $\mathrm{M}_{7} \mathrm{C}_{3}$-carbides and that of the MC-carbides in the $Y$ direction in $\mathrm{BE}$ detection regime are significantly different from the mean value of the linear fractions of the $\mathrm{M}_{7} \mathrm{C}_{3^{-}}$(or MC-) carbides in the $Y$ direction in $\mathrm{SE}$ detection regime.

- The mean value of the linear fractions of the $\mathrm{M}_{7} \mathrm{C}_{3}$-carbides and that of the MC-carbides in the $Z$ direction in $\mathrm{BE}$ detection regime are significantly different from the mean value of the linear fractions of the $\mathrm{M}_{7} \mathrm{C}_{3^{-}}$(or MC-) carbides in the $Z$ direction in $\mathrm{SE}$ detection regime.

An example of a diagnostic report from software Minitab with basic statistical characteristics of the statistical testing of the deviation is in Fig. 9. The diagnostic report describes the data files obtained by the analysis of $\mathrm{M}_{7} \mathrm{C}_{3}$-carbides in the $X$ direction in the $\mathrm{BE}$ and $\mathrm{SE}$ detection regime. The chart on the left side of the diagram shows the linear fractions acquired in the $\mathrm{BE}$ detection regime and that on the right side illustrates the linear fractions in the SE detection regime. The green lines in the charts represent the calculated mean values of measured linear fractions of $\mathrm{M}_{7} \mathrm{C}_{3}$-carbides in both the $\mathrm{BE}$ and $\mathrm{SE}$ detec- tion regimes, respectively. The $x$-axis of the chart is the number of a sample or the sample size while the $y$-axis denotes the obtained linear fractions of the carbides for randomly acquired micrographs. As clearly shown, the vertical position of the green line, which represents the mean value obtained in the BE detection regime differs from that obtained in the SE detection regime.

Figure 10 depicts the summary report from Minitab software for the mean value of the measured linear fractions of the $\mathrm{M}_{7} \mathrm{C}_{3}$-carbides in the $\mathrm{BE}$ and $\mathrm{SE}$ detection regime, respectively, for the micrographs acquired in the $X$ direction. This summary report declares the exact results of the statistical testing of the deviation between two electron detection regimes. The pre-determined $p$-value was 0.05 . The calculated $P$ testing character was close to zero, e.g. it was lower than the pre-determined $p$-value. Hence, the criterion of the statistical testing was met, and the null hypothesis was confirmed. In other words, the mean value of the measured linear fractions for $\mathrm{M}_{7} \mathrm{C}_{3}$-carbides acquired in $\mathrm{BE}$ detection regime, and that of $\mathrm{M}_{7} \mathrm{C}_{3}$ -carbides recorded in $\mathrm{SE}$ detection regime were identified to be different. The data representing the standard deviations and the mean value, right part of Fig. 10, assist in making a more clear comparison between the files obtained by the statistical testing of the deviation between $\mathrm{BE}$ and $\mathrm{SE}$ detection regimes. As shown in the histograms here, the distribution of the data in the BE regime differs clearly from the distribution of the data in the SE regime.

In other words, the mean value of the measured linear fractions of the $\mathrm{M}_{7} \mathrm{C}_{3}$-carbides in the $X$ direction in $\mathrm{BE}$ detection regime is significantly different from the mean value of the measured linear fractions of the $\mathrm{M}_{7} \mathrm{C}_{3}$-carbides in the $X$ direction in $\mathrm{SE}$ detection regime.

The statistical testing of the deviation between two electron detection regimes consisted of six tests because the material contained two types of carbides, which was analysed in three independent directions. The summary of the obtained results is shown in Table 2. Here, "No" denotes that there is no significant difference between linear fractions of carbides 
2-Sample Standard Deviation Test for Mean of $\mathrm{M}_{7} \mathrm{C}_{3} \mathrm{BE}$

(a)

$$
\begin{gathered}
\mathrm{X} \text { and SE } \mathrm{X} \\
\text { Summary Report }
\end{gathered}
$$

Do the means differ?

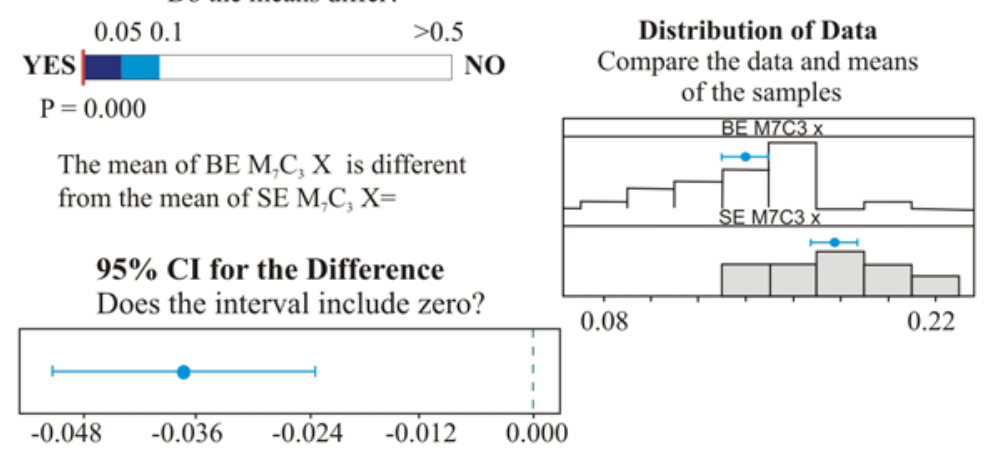

\begin{tabular}{|c|c|c|}
\hline Statistics & BE $\quad M_{7} C_{3}$ & $\mathrm{SE} \quad \mathrm{M}_{7} \mathrm{C}_{3}$ \\
\hline Sample size & 25 & 25 \\
\hline Mean & 0.13984 & 0.17711 \\
\hline $95 \% \mathrm{Cl}$ & $0.1293 ; 0.1504$ & $0.1671 ; 0.1871$ \\
\hline Standard deviation & 0.0255711 & 0.024200 \\
\hline $\begin{array}{l}\text { Difference between means } \\
\quad 95 \% \mathrm{CI}\end{array}$ & $\begin{array}{rl}-(1 & -1 \\
-0.051 & 0\end{array}$ & \\
\hline
\end{tabular}

(b)

Fig. 10. Summary report from Minitab for the mean value of the measured linear fractions of the $\mathrm{M}_{7} \mathrm{C}_{3}$-carbides in $X$ direction in BE vs. SE detection regime: (a) graphs, (b) statistics.

\begin{tabular}{|c|c|c|c|c|c|c|c|c|c|c|c|c|c|}
\hline \multicolumn{14}{|c|}{ BE vs. SE } \\
\hline \multicolumn{7}{|c|}{$\mathrm{M}_{7} \mathrm{C}_{3}$} & \multicolumn{7}{|c|}{$\mathrm{MC}$} \\
\hline & & $X$ & & $Y$ & & $Z$ & & & $X$ & & $Y$ & & $Z$ \\
\hline$X$ & Yes & $P=0.000$ & & - & & - & $X$ & Yes & $P=0.000$ & & - & & - \\
\hline$Y$ & & - & Yes & $P=0.003$ & & - & $Y$ & & - & Yes & $P=0.000$ & & - \\
\hline$Z$ & & - & & - & Yes & $P=0.003$ & $Z$ & & - & & - & Yes & $P=0.000$ \\
\hline
\end{tabular}

Ta b le 2. Summarizing table of results in the BE vs. SE detection regimes

obtained in tested directions and "Yes" represents the case when the difference in linear fractions is statistically significant. As is clearly evident, the $P$ testing characters are lower than the pre-determined $p$-value (0.05), i.e. the null hypothesis was confirmed for all the cases of testing. In other words, one can conclude that the mean values of linear fractions calculated from micrographs acquired in the BE detection regime were significantly different from the mean values of linear fractions obtained from micrographs recorded in the SE detection regime, i.e. there is the difference in detection limit and resolution two detection regimes used.

\subsection{Statistical testing of material isotropy in the secondary electron (SE) detection regime}

Because the results of determination of the linear fraction of carbides in $\mathrm{BE}$ detection regime and those of SE detection regime have shown significant differences, the statistical test of material isotropy also had to be analysed in the secondary electron detection regime. The null hypotheses for statistical testing of isotropy in the secondary electron detection regime are expressed as follows:

- The mean values of the linear fraction of the $\mathrm{M}_{7} \mathrm{C}_{3}$-carbides and those of the MC-carbides in the 
Ta ble 3. Summarizing table of results in the SE detection regime

SE

\begin{tabular}{|c|c|c|c|c|c|c|c|c|c|c|c|}
\hline \multicolumn{6}{|c|}{$\mathrm{M}_{7} \mathrm{C}_{3}$} & \multicolumn{6}{|c|}{$\mathrm{MC}$} \\
\hline & $X$ & & $Y$ & & $Z$ & & $X$ & & $Y$ & & $Z$ \\
\hline$X$ & - & No & $P=0.752$ & No & $P=0.502$ & $X$ & - & No & $P=0.350$ & No & $P=0.971$ \\
\hline$Y$ & - & & - & No & $P=0.324$ & $Y$ & - & & - & No & $P=0.367$ \\
\hline$Z$ & - & & - & & - & $Z$ & - & & - & & - \\
\hline
\end{tabular}

$X$ direction are significantly different from the mean values of the linear fractions of the $\mathrm{M}_{7} \mathrm{C}_{3^{-}}$(or $\mathrm{MC}$ -carbides) in the $Y$ direction.

- The mean values of the linear fraction of the $\mathrm{M}_{7} \mathrm{C}_{3}$-carbides and those of the MC-carbides in the $Y$ direction are significantly different from the mean values of the linear fractions of the $\mathrm{M}_{7} \mathrm{C}_{3^{-}}$(or $\mathrm{MC}$ -carbides) in the $Z$ direction.

- The mean values of the linear fractions of the $\mathrm{M}_{7} \mathrm{C}_{3}$-carbides and those of the MC-carbides in the $X$ direction are significantly different from the mean values of the linear fractions of the $\mathrm{M}_{7} \mathrm{C}_{3^{-}}$(or $\mathrm{MC}$ -carbides) in the $Z$ direction.

The summary of the obtained results is shown in Table 3 . As is clearly evident, the $P$ testing characters are higher than the pre-determined $p$-value (0.05), which means that the null hypothesis was rejected for all the cases of testing. In other words, the differences of mean values of linear fractions in all directions were independent in the SE detection regime as the testing in the BE detection regime.

The manufacturing route of the analysed material is the powder metallurgy of rapidly solidified particles. This process consists of the following steps:

(i) Preparation of powders by atomization of the melt using an inert gas.

(ii) Consolidation of obtained powders via hot isostatic pressing (HIP).

(iii) Hot forming of the compact materials into semi-finished products (sheets, bars, profiles).

The first manufacturing step gives the materials fine microstructure with small carbides (up to $3 \mu \mathrm{m}$ in size) that is almost free of macro-segregations [12, 14]. The use of HIP-technique for the consolidation of powders makes the materials free of carbide banding and/or clustering and one can also expect that their microstructure would be directionally independent, e.g. isotropic. Nevertheless, hot forming is necessary as the final step of the manufacturing route, in order to produce semi-finished products that are then delivered to the end-users. Hot forming, unfortunately, may produce structural anisotropy of the materials, due to preferential material flux resulting from forming direction. Structural anisotropy can lead to the anisotropy in mechanical properties of the materials. Hence, the selection of material direction has to be considered when sampling or making the tools. The obtained results, fortunately, did not confirm the expectations that the hot forming would have led to the certain structural anisotropy of the material and the microstructure of examined steel has shown a high degree of isotropy. Hence, the orientation of semi-finished product (delivered from the steel manufacturer) can be disregarded when sampling, for instance, to carry out the investigations of toughness and fracture toughness of the Vanadis 6 steel.

The obtained results pertaining to the effect of detection regime on the microstructural evaluation can be considered as logical. During the experimental trials, which have been published recently [21] it was recognized that many very fine carbide particles had been missed when $\mathrm{BE}$ detection regime has been used for the investigations. Therefore, the SE detection regime has been successfully applied for precise characterization of the carbides in mentioned paper and, based on the current result, one can also recommend the acquisition of micrographs in the regime of the detection of secondary electrons for further investigations.

\section{Conclusions}

In the current paper, the microstructure with a particular focus on carbides amount in PM ledeburitic cold work tool steel VANADIS 6 was analysed. The quantitative analysis has been carried out in three independent directions using linear quantitative method whereas two detection regimes, namely backscattered electrons and secondary electrons have been adopted for the recording of micrographs. The main results can be summarized as follows:

1. The analysed material contains two main carbide phases, namely the $\mathrm{M}_{7} \mathrm{C}_{3}$-particles and the $\mathrm{MC}$ -particles.

2. The detailed statistical analysis had shown that the linear fractions of both types of carbide phases were directionally independent when the BE detection regime was adopted for the microstructural analysis. The results obtained by the detection of secondary electrons are practically the same.

3. There is statistically significant difference between the linear fractions of carbides determined in 
$\mathrm{BE}$ detection regime and those established in SE detection regime. The difference between these two techniques in terms of their resolution limit has been confirmed.

Two common practical recommendations can be derived from the obtained results. The first one is that the detection of secondary electrons is essential for quantitative microstructural evaluation of fine-grained powder metallurgy ledeburitic steels because of its better resolution limit. The second (and the most important) recommendation is that the orientation of semi-product can be disregarded when sampling or manufacturing the tools because of a high degree of isotropy of the steel Vanadis 6.

\section{Acknowledgement}

This paper is a result of experiments made within the frame of the project VEGA $1 / 0735 / 14$. The authors are grateful for the financial support to the research.

\section{References}

[1] Večko Pirtovšek, T., Kugler, G., Godec, M., Terčelj, M.: Metallurgical and Materials Transactions A, 43, 2012, p. 3797. doi:10.1007/s11661-012-1195-4

[2] Kheirandish, S., Saghafian, H., Hedjazi, J., Momeni, M.: Journal of Iron and Steel Research International, 17, 2010, p. 40. doi:10.1016/S1006-706X(10)60140-9

[3] Bombac, D., Fazarinc, M., Saha Podder, A., Kugler, G.: Journal of Materials Engineering and Performance, 22, 2013, p. 742 . doi:10.1007/s11665-012-0340-y

[4] Večko Pirtovšek, T., Kugler, G., Terčelj, M.: Materials Characterization, 83, 2013, p. 97. doi:10.1016/j.matchar.2013.06.008
[5] Berns, H., Fischer, A., Hoensch, W.: HTM HärtereiTechn. Mitt, 45, 1990, p. 217. (In German)

[6] Grgač, P.: Neue Hutte, 12, 1989, p. 459.

[7] Berns, H., Broeckmann, C., Weichert, D.: Engineering Fracture Mechanics, 58, 1997, p. 311. doi:10.1016/S0013-7944(97)00118-5

[8] Kremnev, L. S., Sapronov, I. J.: Metal Science and Heat Treatment, 701, 2013, p. 3. (In Russian)

[9] Hoyle, G.: High Speed Steels. Cambridge, Butterworth 1988.

[10] Spies, H. J., Frommeyer, G.: Materials Science and Technology, 7, 1991, p. 718 .

[11] Olsson, L. R., Fischmeister, H. F.: Powder Metallurgy, 21, 1978, p. 13. doi:10.1179/pom.1978.21.1.13

[12] Jurči, P., Hnilica, F., Stolař, P.: Kovove Mater., 38, 2000, p. 416.

[13] Jurči, P., Vojtěch, D., Stolař, P.: Zeitschrift fur Metallkunde, 88, 1997, p. 733 .

[14] Jurči, P.: Powder Metallurgy, 41, 1998, p. 269. doi:10.1179/pom.1998.41.4.269

[15] Mesquita, R. A., Barbosa, C. A.: Materials Science and Engineering A, 383, 2004, p. 87. doi:10.1016/i.msea.2004.02.035

[16] VANADIS 6 - Superclean. Company Presentation. Hagfors, UDDEHOLM AB 2000.

[17] Cobb, W. G.: Design and Analysis of Experiments. New York, Springer-Verlag 1999.

[18] Montgomery, C. D., Runger, C., G.: Applied Statistics and Probability for Engineers. Hoboken, John Wiley \& Sons 1999.

[19] Bílek, P., Sobotová, J., Jurči, P.: Materiali in Tehnologije, 45, 2011, p. 489.

[20] Pašák, M., Čička, R., Bílek, P., Jurči, P., Čaplovič, L.: Materiali in Tehnologije, 48, 2014, p. 693.

[21] Jurči, P., Dománková, M., Caplovič, L., Ptačinová, J., Sobotová, J., Salabová, P., Prikner, O., Suštaršič, B., Jenko, D.: Vacuum, 111, 2015, p. 92. doi:10.1016/j.vacuum.2014.10.004 